Disponível em

http://www.anpad.org.br/rac

RAC, Rio de Janeiro, v. 18, n. 3, art. 4, pp. 311-327, Maio/Jun. 2014 http://dx.doi.org/10.1590/1982-7849rac20141612

(cc) BY-NC

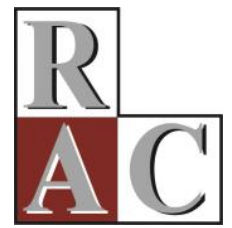

\title{
Motivações para o Empreendedorismo: Necessidade Versus Oportunidade?
}

Motivations for Entrepreneurship: Necessity Versus Opportunity?

Gláucia Maria Vasconcellos Vale E-mail: galvale@terra.com.br

Pontifícia Universidade Católica de Minas Gerais - PUCMinas Av. Itaú, 525, Dom Cabral, 30535-012, Belo Horizonte, MG, Brasil.

Victor Silva Corrêa

E-mail: correavictor@oi.com.br Pontifícia Universidade Católica de Minas Gerais - PUCMinas Av. Itaú, 525, Dom Cabral, 30535-012, Belo Horizonte, MG, Brasil.

Renato Francisco dos Reis E-mail: reisestatistica@uai.com.br Universidade do Estado de Minas Gerais - UEMG Rua Major Lopes, 574, São Pedro, 30330-050, Belo Horizonte, MG, Brasil. 


\title{
Resumo
}

Alguns autores consideram que as pessoas podem ser levadas ao empreendedorismo seja pelo motivo oportunidade, seja pelo motivo necessidade, alternativamente. Outros, uma minoria, vêm sugerindo que as motivações não possuem uma natureza dicotômica, que outros motivos poderiam intervir no processo e que poderia, eventualmente, ocorrer reforço ou interação entre diferentes motivos. O presente artigo insere-se no contexto dessas reflexões. Busca, por meio de uma pesquisa qualitativa associada a uma quantitativa, identificar os motivos intervenientes na criação de novos empreendimentos. Enquanto a primeira sugere a possibilidade de motivações múltiplas, a segunda - construída a partir de referências aí geradas - atesta a presença de tais motivações. Os resultados indicam que os motivos ultrapassam a lógica binária oportunidade versus necessidade, incluindo: oportunidade, atributos pessoais, mercado de trabalho, insatisfação com emprego, família e influência externa.

Palavras-chave: empreendedorismo; abertura de nova empresa; motivação; necessidade; oportunidade.

\begin{abstract}
Most research purports to show the prevalence of either need or opportunity as the driving motive for entrepreneurship. Some has suggested that there is no such dichotomy; other motives can interfere, with interaction among them. This paper delves into such matters insofar as it brings to bear a qualitative research associated with a quantitative one, both targeted to identify the motives underlying the genesis of new undertakings. While the first procedure suggests the presence of multiple motives, the second - built from generated references - ratifies the occurrence of such motives. Results suggest that underlying motives bypass the binary conundrum of need versus opportunity and go deeper, in order to include: opportunity, personal attributes, labor markets, job frustration, family pressures, and external influences.
\end{abstract}

Key words: entrepreneurship; new undertaking; motivation; necessity; opportunity. 


\section{Introdução}

Nos últimos anos, ganharam força, nas literaturas internacional e nacional, investigações acerca dos motivos que levam os indivíduos à atividade empreendedora (Antunes et al., 2012; Block \& Sandner, 2009; Block \& Wagner, 2010; Gartner, 1989; Kautonen \& Palmoroos, 2010; Sivapalan \& Balasundaram, 2012; Smallbone \& Welter, 2001; Townsend, Busenitz, \& Arthurs, 2010; Ummah \& Gunapalan, 2012; Williams \& Round, 2009), com destaque para a temática necessidade versus oportunidade. Embora tal tema tenha sido abordado em investigações prévias, inclusive no Brasil (Nutin, 1984; Valarelli \& Vale, 1997; Vale, Aguiar, \& Andrade, 1998), parte do interesse mais recente por esse assunto advém de dois fatos, em particular. Por um lado, a expansão de experiências associadas ao empreendedorismo, em todo o mundo. Como observado por Lohrke e Landström (2010, p. 1), o crescimento desse campo de pesquisas acompanhou e "foi reforçado por fatores externos, a exemplo de políticas governamentais de estímulo ao empreendedorismo em vários lugares do mundo". Por outro, o impacto e a influência das pesquisas conduzidas, em nível internacional, no contexto do Global Entrepreneurship Monitor (GEM). O projeto GEM inclui, atualmente, cerca de 60 países, e é considerado "o maior estudo contínuo sobre a dinâmica empreendedora no mundo" (Duarte et al., 2011, p. 87). No Brasil, a pesquisa vem sendo conduzida, desde o ano 2000, pelo IBQP, em parceria com o Centro de Empreendedorismo e Novos Negócios da Fundação Getúlio Vargas, contando com o apoio do Sebrae e de outras entidades.

O GEM propõe-se a medir, entre outras variáveis, a parcela de indivíduos que, em cada país, lança-se ao empreendedorismo, e a "avaliar os motivos dos empreendedores" (GEM, n.d.). Como salientado pelo GEM, pessoas podem ser levadas ao empreendedorismo por dois motivos alternativos: necessidade ou oportunidade. Tais motivações permitiriam enquadrar o empreendedor em duas categorias distintas, mutuamente excludentes: empreendedores por necessidade e empreendedores por oportunidade. Os empreendedores por necessidade representariam uma "parcela da população envolvida com o empreendedorismo por não ter outra opção de trabalho" (GEM. 2011, p. 89). Já os empreendedores por oportunidade formariam a parcela da população "envolvida com o empreendedorismo não por não ter outra opção de trabalho, e, sim, por ter identificado uma oportunidade de negócio que pretende perseguir" (GEM, 2011, p. 89). O empreendedor movido por oportunidade "é capaz de escolher um empreendimento dentre as opções possíveis de carreiras" (Reynolds, Bygrave, \& Autio, 2002, p. 20). Segundo responsáveis pelo projeto, seria possível "classificar mais de $97 \%$ daqueles indivíduos ativamente envolvidos em alguma atividade empreendedora como empreendedores motivados por oportunidade ou por necessidade" (Reynolds et al., 2002, p. 20).

Muitos outros autores, não ligados ao projeto GEM, também vêm adotando uma linha semelhante (Block \& Sandner, 2009; Block \& Wagner, 2010; Llisterri, Kantis, Angelelli, \& Tejerina, 2006; Williams, 2008; Williams, Round, \& Rodgers, 2009). Prevalece, nesse contexto, a noção de que as pessoas podem ser movidas seja por necessidade ou, então, por oportunidade, mas, nunca, pelos dois motivos ao mesmo tempo. Empreendedores são considerados, antes de tudo, indivíduos atentos às oportunidades (Kirzner, 1979). Para Aldrich e Cliff (2003), estudiosos do empreendedorismo finalmente concordam que "um aspecto fundamental do empreendedorismo envolve a identificação de oportunidades" (p. 572), traduzida, frequentemente, por meio da criação de um novo empreendimento. Mas isso não é tudo. Observam-se, no mundo contemporâneo, mudanças drásticas nos sistemas produtivos e no mercado de trabalho. Ao lado do fantasma do desemprego, que assola as economias modernas, existe, também, uma mudança no perfil da mão de obra ocupada, com acréscimo no número de trabalhadores autônomos (Aranson, 1991; Kon, 2001; Plehn-Dujowich, n.d.; Secretaria de Assuntos Estratégicos, 2013; Serviço Brasileiro de Apoio às Micro e Pequenas Empresas [Sebrae], 2013). Nesse ambiente, muitos vislumbram, no empreendedorismo, uma via possível de inserção social e profissional (Zalio, 2011). Mas seriam os motivos oportunidade e necessidade realmente excludentes entre si ou, mesmo, únicos?

Ao longo do tempo, alguns estudos vêm partindo do pressuposto - embora não testado- de que as motivações para empreender poderiam não ser, exatamente, excludentes entre si, ou, mesmo, que 
apresentariam uma natureza mais complexa e multidimensional, extrapolando o tema necessidade e oportunidade (Nutin, 1984; Sebrae, 2007a, 2007b; Sivapalan \& Balasundaram, 2012; Ummah, 2009; Valarelli \& Vale, 1997; Vale et al., 1998). Como salientado por Friedman (1986), o empreendedorismo seria função de estímulo ambiental, oportunidade e necessidade. Nesse contexto, as motivações para empreender poderiam, na verdade, ser múltiplas e poderia, eventualmente, ocorrer interação ou reforço entre elas. O presente artigo insere-se no contexto dessas reflexões. Busca, por meio de uma investigação empírica, realizada junto a 170 empreendedores, identificar os motivos que, na ótica desses atores, foram importantes na criação de seus empreendimentos. Utiliza, para isso, as seguintes hipóteses: $\mathrm{H}_{0}$ : oportunidade e necessidade abarcam o conjunto de motivações para a criação de uma empresa; $\mathrm{H}_{1}$ : oportunidade e necessidade não abarcam o conjunto de motivações para a criação de uma empresa. Para efeito deste trabalho, considera-se empreendedor aquele que "cria uma empresa" (Gartner, 1989, p. 47). Assim, considera-se empreendedor por oportunidade aquele que abre uma empresa movido pela crença na identificação de uma oportunidade de negócio. Considera-se empreendedor por necessidade, por sua vez, aquele que abre uma empresa pressionado pela ausência de alternativas de trabalho e renda.

O artigo encontra-se dividido em quatro partes. Na primeira, é apresentado o referencial teórico. $\mathrm{Na}$ segunda, a metodologia utilizada. Na terceira, são apresentados os principais resultados da investigação, e, finalmente, na quarta, as considerações finais. Observa-se que o presente artigo distingue-se da literatura existente, em pontos importantes. Em primeiro lugar, por incorporar e avaliar duas visões bastante distintas - baseadas em diferentes pressupostos - e tratadas separadamente na literatura. De um lado, a visão centrada em oportunidade e necessidade; de outro, a visão baseada na noção de motivações múltiplas e, eventualmente, interdependentes. Em segundo lugar, ao associar uma análise de natureza quantitativa - baseada em análise fatorial - com uma qualitativa. Isso permite melhor identificar e caracterizar a complexidade, a riqueza e as nuances das motivações empreendedoras. Enquanto a pesquisa qualitativa sugeriu a presença de diferentes motivações, de possíveis interações entre elas e gerou as referências para a quantitativa, esta, por sua vez, atestou que os motivos são múltiplos, ultrapassando a lógica binária oportunidade e necessidade, incluindo: oportunidade, atributos pessoais, mercado de trabalho, insatisfação com emprego, família e influência externa. Em terceiro lugar, por trazer novos elementos para análise do fenômeno, observa-se que a atual pesquisa identificou a influência do fator familiar entre as motivações, já que uma parcela não desprezível dos entrevistados alegou, por exemplo, ter criado uma empresa visando dar ocupação a membros da família. Embora restrita a determinado universo de interesse, a pesquisa permite sugerir que visões dicotômicas, baseadas no pressuposto que apenas duas motivações - oportunidade e/ ou necessidade - abarcariam, praticamente, todo o universo de interesse, podem limitar a observação do fenômeno de interesse.

\section{Referencial Teórico}

A busca mais sistemática dos motivos que levam indivíduos à determinada atividade produtiva teve início a partir da década de 1950, influenciada, sobretudo, por contribuições geradas na área da psicologia (Festinger, 1957, McClelland, 1972). Tais estudos, na área do empreendedorismo, enfocaram, inicialmente, certos traços ou atributos intrínsecos ao indivíduo (McClelland, 1972). Um exemplo mais recente dessa vertente pode ser representado pelos trabalhos de Ummah e Gulapalan (2012). Ao longo do tempo, outros motivos, de natureza extrínseca, foram enfatizados (Sivapalan \& Balasundaram, 2012). Nesse contexto, um fator, em particular, vem ganhando vulto na literatura recente. Trata-se do tema do desemprego (Kautonen \& Palmroos, 2010; Sivapalan \& Balasundaram, 2012; Zalio, 2011). Motivos intrínsecos e extrínsecos podem, inclusive, interagir entre si (Nuttin, Lorion, \& Dumas, 1984; Townsend et al., 2010). No esteio das reflexões sobre motivações empreendedoras, advém a temática oportunidade versus necessidade. 


\section{Oportunidade ou necessidade}

A visão de empreendedores como pessoas atentas às oportunidades encontra guarida no pensamento econômico neoclássico. Para Kirzner (1979), o empreendedor é aquele que se encontra sempre em estado de alerta, para descobrir e explorar novas oportunidades. Esta capacidade de estar alerta constituir-se-ia a principal característica de tais indivíduos. São, sempre, os primeiros a identificar oportunidades lucrativas de negócios. Sabem comprar em um determinado local e vender em outros ou em momentos distintos; compram insumos e vendem produtos processados, etc. Segundo Woods (2006), Kirzner (1979) foi o primeiro pensador a articular uma teoria do empreendedor baseada no conceito de alerta. Na visão de Kirzner (1979), a capacidade de estar alerta expressaria e refletiria, inclusive, motivações pessoais, aspirações e sonhos do próprio empreendedor. Ao incorporar, em suas proposições, o tema das aspirações e das motivações pessoais, Kirzner (1979), de certa forma, aproximase do cerne das preocupações de outro expoente da área de empreendedorismo. Trata-se de McClelland (1972).

Para McClelland (1972), são os valores, as motivações humanas e a necessidade de autorrealização que movem indivíduos na busca de atividades empreendedoras. Entre os principais motivos que impulsionam o indivíduo a agir, situa-se a necessidade de conquistas e realizações. Ou seja, "um desejo de realizar as coisas da melhor maneira, não exatamente pelo reconhecimento social ou prestígio, mas, sim, pelo sentimento íntimo de necessidade de realização pessoal" (McClelland, 1972, p. 110). Indivíduos com elevado nível de necessidade de realização e conquista apresentam maior propensão a perseguir desafios, de maneira relativamente autônoma. Como salientado por Schatz (1971, p. 183), tais pessoais possuem "uma propensão particularmente forte a apresentar bom desempenho em situações nas quais indivíduos esperam ser avaliados por padrão superior de desempenho". São esses os indivíduos talhados para o empreendedorismo. Eles almejam e buscam autonomia, independência e desafios moderados. Para Baum, Frese, Baron e Katz (2007), os estudos de McClelland (1972) influenciaram toda uma geração de estudiosos do empreendedorismo. Seus seguidores, ainda hoje, continuam a buscar os traços pessoais distintivos que impulsionariam os indivíduos ao empreendedorismo.

Reflexões emblemáticas, do tipo aqui apresentado (Kirzner, 1979; McClelland, 1972), permitem caracterizar o empreendedor como um indivíduo movido pela busca da autonomia pessoal e atento às oportunidades. No mundo corrente, caracterizado por um tipo de desemprego estrutural, observa-se, de maneira crescente, a presença, também marcante, de um tipo de empreendedor movido, não necessariamente pela oportunidade, e, sim, pela necessidade de sobrevivência. Indivíduos muitas vezes sem condições de se inserir, de maneira adequada, no mercado formal de trabalho, dirigem-se para a atividade empreendedora. Buscam uma alternativa possível de trabalho e geração de renda (Sivapalan \& Balasundaram, 2012; Zalio, 2011). Como salientado pelo GEM (Reynolds et al., 2002, p. 20), tais indivíduos seriam, em oposição àqueles movidos por oportunidades, de "certa maneira, forçados a iniciar seus próprios negócios porque inexistem quaisquer outras opções de trabalho ou porque as existentes são insatisfatórias". De um lado, situar-se-ia o indivíduo motivado por oportunidade e, no outro, aquele movido por pressão do desemprego, por exemplo. Eventualmente, diferenças de motivação poderiam refletir diferenças em termos de perfil ou de desempenho individual (Block \& Sandner, 2009; Block \& Wagner, 2010; Kautonen \& Palmroos, 2010). No entanto, nem todos os estudos permitem tais constatações (Sebrae, 2007a, 2007b).

\section{A tensão entre as motivações e a complexidade}

Alguns estudos avançam além do dualismo do GEM, sugerindo a presença de certa tensão ou interação entre os motivos necessidade e oportunidade (Williams, 2008; Williams et al., 2009; Williams $\&$ Round, 2009). Williams e Round (2009), por exemplo, em uma pesquisa quantitativa realizada junto a 313 moradores de Moscou, incluindo 81 empreendedores informais, mostraram que, em apenas 17\% do total, a necessidade ou a oportunidade poderiam ser consideradas a motivação exclusiva para a atividade empreendedora. Na maioria das vezes $-83 \%$ do total - prevaleceu a copresença de ambos os motivos. Como salientado pelos autores (Williams \& Round, 2009), haveria necessidade de superação 
do dualismo centrado em oportunidade e necessidade, que deveria ser "substituído por uma nuance mais compreensiva da rica e dinâmica motivação presente nas decisões” (p. 211).

Outros vêm sugerindo que as motivações para empreender extrapolam o tema oportunidade e necessidade (Sebrae, 2007a, 2007b; Sivapalan \& Balasundaram, 2012; Smallbone \& Welter, 2001; Storey, 2006; Ummah \& Gunapalan, 2012; Vale et al., 1998; Williams et al., 2009; Williams \& Round, 2009; Woods, 2006). Cada autor elenca um conjunto de motivos. Para Storey (2006), por exemplo, os motivos ou fatores que influenciam a escolha entre se tornar ou não um empreendedor são três: talento, atitude face ao risco e fatores pessoais. Ummah e Gunapalan (2012), enfocando fatores pessoais e sucesso, identificam três (personalidade, background familiar e suporte institucional). Pozin (2013) trabalha com 10 motivos, incluindo: oportunidade, autonomia, liberdade, realização, família (especificamente, mais tempo e flexibilidade para cuidar da família), etc. Vale, Aguiar e Andrade (1998) utilizam 12 motivos. O Sebrae (2007a, 2007b) utiliza 13 motivos.

Esses estudos, em sua maioria, abraçam o pressuposto da motivação múltipla, sem maiores preocupações com uma aferição prévia. Pesquisa realizada pelo Sebrae (2007a, 2007b), por exemplo, em todas as Unidades da Federação, sugere a interação entre diferentes motivos. Entre as empresas extintas (Sebrae, 2007a), 70\% dos antigos proprietários alegaram ter aberto sua empresa movidos pelo desejo de aumentar a renda; $60 \%$ pelo desejo de ter seu próprio negócio; $40 \%$ pela identificação de uma oportunidade de negócios, etc. Observa-se que a soma das parcela obtidas em cada um dos motivos é muito superior ao total de respondentes (100\%). Isso indica que um mesmo indivíduo alegou ter sido movido ao empreendedorismo por mais de um motivo, ao mesmo tempo.

Observa-se, em alguns desses estudos, uma certa primazia - embora não exclusividade - dos motivos oportunidade e necessidade e, também, uma interação entre diferentes motivos. É o caso de Vale et al. (1998), em um estudo envolvendo 775 indivíduos que haviam criado um empreendimento, no estado de Minas Gerais. Embora a pesquisa procure distinguir os empreendedores bem-sucedidos (suas empresas continuavam no mercado) daqueles que fracassaram em suas iniciativas (suas empresas fecharam ou desapareceram), os motivos alegados pelos dois grupos não apresentam grandes diferenciações entre si. O motivo identificação de uma oportunidade de negócios foi o mais citado, por ambos. No entanto, esse motivo, muitas vezes, não se apresentou de maneira isolada. Em parcela significativa de casos, ele aparece de forma concomitante a outros motivos, também colocados, pelo empreendedor, em patamar semelhante de importância. Valarelli e Vale (1997), em um estudo conduzido junto a empreendimentos populares, localizados nos aglomerados da cidade do Rio de Janeiro, destacam a importância do motivo oportunidade, mas apresentam-no, algumas vezes, de maneira associada a outros motivos, incluindo a pressão do desemprego, entre outros.

Os motivos elencados na literatura podem ser, como já salientado, intrínsecos ou extrínsecos ao indivíduo (Sivapalan \& Balasundaram, 2012), baseados em habilidades pessoais ou em expectativas de resultados (Townsend et al., 2010). Independentemente de sua natureza, a motivação para empreender, no mundo de hoje, manifesta-se no contexto de moderna economia de mercado. Embora tal sistema - e seus desdobramentos em termos de valores associados à autonomia e à independência individual predomine em grande parte do mundo, ele coexiste com outros sistemas de interação social/econômica (Barber, 1995), incluindo um, de interesse particular do presente trabalho. Trata-se do que Barber (1995) designou por sistema de redistribuição, em contraposição ao sistema hoje dominante de mercado. Observa-se, antes de mais nada, que esse autor não estava diretamente interessado na temática do empreendedorismo e, sim, na identificação e na compreensão dos três diferentes sistemas de interação social e econômica existentes no mundo (mercado, reciprocidade e redistribuição. Segundo o autor, o sistema de redistribuição ocorre quando existe um ator central que, mesmo inserido em uma moderna economia de mercado, redistribuiu recursos para outros autores periféricos. Na dimensão de interesse do presente trabalho, tal fenômeno poderia ser representado pela iniciativa de indivíduos que decidem criar empreendimentos movidos pelo desejo de gerar emprego/ocupação para seus familiares. Um exemplo seria o caso de um pai que cria uma empresa visando tornar seu filho produtivo.

O conjunto de reflexões aqui realizadas permite sugerir não apenas a possibilidade de haver certa tensão entre oportunidade e necessidade, como, também, a possibilidade das motivações poderem ser 
mais complexas e diversificadas. Tais considerações nortearam a pesquisa de campo, que contou com o recurso de uma metodologia diferenciada.

\section{Metodologia de Pesquisa}

A coleta de dados ocorreu em dois momentos distintos. Foi realizada, primeiramente, uma pesquisa qualitativa, de natureza exploratória, não probabilística e não estruturada, junto a 45 empreendedores do setor industrial, presentes no município de Belo Horizonte. Buscou-se identificar quais haviam sido os motivos que os levaram à criação de seus empreendimentos. Esses dados foram tratados de duas maneiras distintas. Em primeiro lugar, alguns casos, considerados mais interessantes, da ótica do pesquisador, foram selecionados e tratados. Alguns são mencionados no presente trabalho, com o propósito, exclusivo, de enriquecer resultados quantitativos. Em segundo lugar, os motivos elencados foram analisados pelo método de análise de conteúdo (Bardin, 2004), a partir de categorias de motivos previamente identificadas na literatura. Comparando-se os motivos identificados na pesquisa de campo com as categorias de motivos levantadas na literatura, houve necessidade de se proceder a alguns ajustamentos. Alguns dos motivos mencionados na literatura foram abandonados na segunda etapa da pesquisa, a exemplo de um utilizado pelo Sebrae (aproveitar incentivos governamentais), pois o mesmo teve índice de resposta zero, tanto na pesquisa conduzida pelo Sebrae, quanto nessa primeira etapa de pesquisa de campo. Ao mesmo tempo, outros motivos, não identificados previamente na literatura, foram encontrados no campo, e, então, incorporados à presente pesquisa: continuidade ou ampliar os negócios da família; possibilidade de usar experiência/ influência familiar; possibilidade de usar relacionamentos e contatos na área; dar ocupação a membros da família. A partir daí foi gerada uma relação composta por 15 diferentes motivos, incluindo os extraídos da literatura e os novos, identificados na primeira fase da pesquisa, ainda que não encontrados, previamente, na literatura.

São eles: (a) identificação de uma oportunidade de negócio (Duarte et al., 2011; Llisterri et al., 2006; Pozin, 2013; Smallbone \& Welter, 2001; Storey, 2006; Williams \& Round, 2009; Woods, 2006); (b) desemprego (Llisterri et al., 2006; Sebrae, 2007a, 2007b; Sivapalan \& Balasundaram, 2012; Smallbone \& Welter 2001; Ummah \& Gunapalan, 2012; Vale et al., 1998; Williams et al., 2009); (c) dar continuidade ou ampliar os negócios da família (pesquisa de campo); (d) possibilidade de usar experiência ou influência familiar (pesquisa de campo); (e) possibilidade de usar relacionamentos e contatos na área (pesquisa de campo); (f) desejo de dar ocupação a membros da família (pesquisa de campo); (g) convite para participar como sócio da empresa (Vale et al., 1998); (h) desejo de ter um negócio próprio/tornar-se independente (Pozin, 2013; Sebrae, 2007a; Sivapalan \& Balasundaram, 2012; Ummah \& Gunapalan, 2012; Vale et al., 1998); (i) insatisfação com emprego (Sebrae, 2007a; Ummah \& Gunapalan, 2012; Vale et al., 1998); (j) presença de capital disponível (Llisterri et al., 2006; Sebrae, 2007a; Vale et al., 1998); (k) tempo disponível (Sebrae, 2007a; Vale et al., 1998); (1) acesso a recursos do Fundo de Garantia do Tempo de Serviço (Sebrae, 2007a; Vale et al., 1998); (m) inserção em programa de demissão voluntária (Sebrae, 2007a; Vale et al., 1998); (n) aumentar renda (Sebrae, 2007a; Vale et al., 1998); (o) influência de terceiros (Sebrae, 2007a; Vale et al., 1998).

Essa relação, complementada por um item final (outros motivos) - visando captar eventuais motivos, não listados anteriormente - foi utilizada na segunda etapa da pesquisa de campo. Essa etapa foi conduzida junto a uma amostra representativa da população, composta por 170 empreendedores do setor industrial, presentes em Belo Horizonte. A amostra, de natureza aleatória simples, sem reposição, foi extraída de universo composto por 4.100 empreendedores, integrantes do cadastro de empresas da Federação das Indústrias do Estado de Minas Gerais (FIEMG), sendo 98\% delas micro e pequenas empresas. Estima-se que essas empresas representassem cerca de $50 \%$ do total de indústrias existentes no município. Observa-se que a base industrial de Belo Horizonte é composta, sobretudo, por pequenas empresas de setores tradicionais, como confecções, calçados, artigos de couro, laticínios, alimentação, móveis e metalurgia. Os dados foram coletados através de questionários estruturados, seguidos de entrevistas, junto aos sócios-proprietários. Trabalhou-se com nível de confiança de $97 \%$ e erro amostral de dez pontos percentuais (Stevenson, 2001). 
Quando um dos empreendedores selecionados para a amostra não conseguia ser entrevistado, ele era, então, substituído por um segundo, extraído aleatoriamente da população. Os empreendedores foram, inicialmente, solicitados a imputar uma nota, variando de 1 a 5, segundo a importância dos motivos previamente elencados. Assim, a nota 5 iria significar que o motivo em questão foi por ele considerado muito importante. A nota 4 como importante e assim, sucessivamente, até a nota 1, que indicava a irrelevância do motivo. Esses dados foram utilizados, posteriormente, para as análises quantitativas. Em seguida, foi solicitado, a cada empreendedor, que falasse sobre a criação de seu empreendimento. Essas informações foram registradas e, a partir daí, foram selecionados e tratados os casos julgados mais interessantes, da ótica do pesquisador.

A análise preliminar dos dados sugeriu a presença de interação e sobreposição entre alguns dos motivos elencados. Decidiu-se, então, disponibilizar as 15 opções fechadas de respostas na escala Likert e de se proceder a uma análise fatorial (AF). O propósito dessa análise seria identificar estruturas de relacionamentos e verificar se essas poderiam ser interpretadas de maneira condizente com pressupostos aqui explicitados.

A análise fatorial é uma técnica estatística multivariada, que busca, através de um conjunto de variáveis, a identificação de dimensões de variabilidade comuns, existentes em um conjunto de fenômenos. O intuito é desvendar estruturas existentes, mas que não são observáveis diretamente. Cada uma dessas dimensões é denominada fator (Corrar, Paulo, \& Dias, 2007). Nesse estudo, pretendeu-se extrair fatores que permitissem compreender o que motiva os empresários na criação de suas empresas. Para Corrar, Paulo e Dias (2007), o método de componentes principais utilizado para extração de fatores não possui a restrição de normalidade multivariada. Considera-se, também, que a matriz de dados tenha correlações suficientes para aplicação da AF. Assim, numa percepção visual, a predominância de correlação acima de 0,30 indicaria indícios de inadequação da aplicação da AF.

Para análise dos dados, foram utilizadas a avaliação da ausência de respostas; a avaliação da consistência interna através do coeficiente alfa de Cronbach; e a aplicação da análise fatorial exploratória para identificação de construtos referentes aos motivos da criação da empresa (Hair, 2005). Para verificar a aleatoriedade dos dados perdidos, se ocorrem completamente ao acaso, aplicou-se o teste MCAR, que resultou nos valores (Little's MCAR test: Chi-Square $=155.095, D F=162$, Sig. =0,638), indicando que os dados perdidos podem ser considerados completamente ao acaso. Para avaliar a confiabilidade desse bloco de questões, utilizou-se o coeficiente Alpha de Cronbach, que é uma das propostas para identificação da consistência interna do instrumento de análise. Define-se a confiabilidade como a representação do grau em que uma escala produz resultados consistentes entre medidas repetidas ou, então, equivalentes de um mesmo objeto ou pessoa, revelando a ausência de erro aleatório. É um modelo de consistência interna baseada na correlação média entre os itens (Corrar et al., 2007). Para os dados dessa pesquisa, o coeficiente alfa de Cronbach foi de 0,661 , resultado que indica boa consistência interna.

Os testes aplicados para a identificação da adequação da AF são o teste de Bartlett de esferecidade, que avalia a presença de correlação entre as variáveis. Outra medida de adequação é MSA (medida de adequação da amostra), proposta por Kaiser-Meyer-Olkin (KMO), que é um índice que varia de 0 a 1 , representando o grau de explicação dos dados, com base nos fatores encontrados na AF. Valores menores ou iguais a 0,5 considera-se inadequada a aplicação da AF. Segundo Hair (2005, p. 98), “é de responsabilidade do pesquisador garantir que os padrões observados sejam conceitualmente válidos e apropriados para estudos com análise fatorial, pois a técnica não tem meio algum para determinar a adequação além das correlações entre variáveis".

Referindo-se ao uso de métodos alternativos para as rotações fatoriais, Hair (2005, p. 106) observa que "nenhuma regra específica foi desenvolvida para guiar o pesquisador na seleção de uma técnica ortogonal ou oblíqua em particular". Para Damásio (2012), as rotações fatoriais podem ser de duas ordens: ortogonais ou oblíquas. Dentre os métodos ortogonais, o varimax é o mais bem sucedido e o mais comumente utilizado. Cabe ressaltar que se avaliaram os resultados a luz dos dois métodos, não existindo diferenciação na formação dos componentes. Por escolha do pesquisador, decidiu-se utilizar, no presente artigo, o método varimax. 
Observa-se, finalmente, que a presente pesquisa difere, em termos de escopo, da realizada pelo GEM. Esta última considera que o empreendedorismo representa qualquer tentativa de criação de um negócio ou um novo empreendimento, como, por exemplo, uma atividade autônoma, uma nova empresa ou a expansão de um empreendimento existente (Antunes et al., 2012). Tais iniciativas podem ser implementadas seja por indivíduos, grupos de pessoas ou empresas já constituídas. Esse conceito é bem mais abrangente do que o utilizado neste trabalho. No caso aqui enfocado, a categoria de interesse (empreendedores como indivíduos que abrem um empreendimento) representaria parcela do conjunto de interesse do GEM (empreendedores como atores de natureza física ou jurídica, que se lançam a quaisquer iniciativas associadas ao empreendedorismo). Consequentemente, os motivos identificados e elencados no presente trabalho poderiam, perfeitamente, distinguir-se daqueles identificados pelo GEM.

\section{Resultados Obtidos}

A pesquisa qualitativa sinalizou para a presença de motivações múltiplas - algumas, inclusive, não abordadas, previamente, na literatura, a exemplo do desejo de gerar ocupação para familiares - e, também, de possíveis interações entre elas. A pesquisa quantitativa, construída a partir de referências geradas pela anterior, permitiu, por sua vez, avançar nas investigações e atestar a presença de motivações múltiplas.

A busca da autonomia individual e a identificação de uma oportunidade de negócios foram os motivos preponderantes encontrados na pesquisa quantitativa. Um total de $74 \%$ dos empreendedores pesquisados considerou o motivo desejo de ter o próprio negócio/tornar-se independente como muito importante. Tal motivo é seguido, de perto, pela identificação de uma oportunidade, julgada muito importante por $68 \%$ deles. Por outro lado, a necessidade de ampliar a renda foi, também, citada como muito importante, por uma parcela significativa do total: $66 \%$. A pesquisa mostrou o impacto do fator desemprego. Um total de $12 \%$ dos indivíduos afirmou ter sido movido ao empreendedorismo por se encontrar desempregado. A criação de uma empresa, motivada pelo desejo de gerar ocupação a membros de família, foi citado por $15 \%$ dos empreendedores. Observa-se que essa motivação não é, necessariamente, focada nos interesses diretos do empreendedor, mas, sim, dirigida para atender necessidades de terceiros, ligados ao empreendedor por vínculos de natureza afetiva e familiar. A Tabela 1 a seguir apresenta os resultados obtidos para o conjunto dos motivos considerados muito importantes (escala 5).

Tabela 1

\section{Motivos Indutores do Empreendedorismo*}

\begin{tabular}{lc}
\hline Motivos & Total de respondentes ** \\
\hline 1- Desejo de ter próprio negócio/tornar-se independente & 74,5 \\
2- Identificação de uma oportunidade de negócio & 68,7 \\
3- Aumento da renda & 66,3 \\
4-Facilidade ou possibilidade de usar os conhecimentos/relacionamentos e contatos & \\
na área & 52,8 \\
5- Presença de tempo disponível & 47,5 \\
6- Continuidade/ Ampliação dos negócios da família & 26,4 \\
7- Experiência/ influência/ relacionamentos familiares & 25,8 \\
8- Convite para participar como sócio da empresa & 25,2 \\
\hline
\end{tabular}




\section{Tabela 1 (continuação)}

\begin{tabular}{lc}
\hline Motivos & Total de respondentes ** \\
\hline 9- Presença de capital disponível & 23,9 \\
10- Insatisfação com emprego & 19,6 \\
11- Influência de outras pessoas & 15,3 \\
12- Ocupação a membros da família & 15,3 \\
13- Desemprego & 12,3 \\
14- Demissão com FGTS & 9,2 \\
15- Aproveitamento programa de demissão voluntária & 3,7 \\
\hline
\end{tabular}

Nota. *Motivos considerados muito importantes pelos empreendedores (nota 5 na escala utilizada); questão permitia múltiplas respostas; **Percentual indica número de respondentes em cada motivo: total de entrevistados.

Analisando-se a Tabela 1, observa-se que o total de citações é muito superior ao total de respondentes, o que indica que um entrevistado considerou importante mais de um motivo ao mesmo tempo (questão permitia múltiplas respostas). Tal resultado já sinaliza para a presença de sobreposições e interações entre os motivos. Tal constatação torna-se ainda mais evidente na análise dos casos selecionados, a exemplo de um indivíduo (empreendedor 1), que trabalhava como empregado em uma metalurgia. Pressionado pela necessidade de aumentar sua renda pessoal, inclusive pela vontade de constituir família, começou a ficar atento às oportunidades, até que, finalmente, consegue vislumbrar uma maneira de abrir o seu próprio negócio. Ou, ainda, o caso de outro indivíduo (empreendedor 2), que trabalhava em uma grande empresa e decidiu abrir um empreendimento próprio, em uma área associada ao seu trabalho, visando complementar sua renda como empregado e poder, dessa maneira, melhor sustentar sua família. Quando seu negócio começou a prosperar, cortou os vínculos com seu empregador e passou a dedicar-se, exclusivamente, à sua empresa.

Um caso que, a princípio, extrapola a lógica mais linear de oportunidade ou necessidade pode ser observado com outro empreendedor (empreendedor 3), que criou um empreendimento visando dar ocupação a um de seus filhos que, apesar de adulto, não conseguia arrumar emprego e tornar-se independente. A criação da empresa foi motivada pelo sentimento da necessidade de garantir ao filho perspectiva profissional e autonomia financeira. Hoje, pai e filho tocam juntos o empreendimento. Outro caso pode ser observado com a empreendedora 4, hoje sócia-proprietária de uma empresa localizada próxima ao seu local de residência. Antes de abrir sua própria empresa, exercia, com grande dedicação, uma função gerencial, bem remunerada, em uma grande empresa. Com o casamento e a chegada do primeiro filho, viu-se pressionada, sobretudo, pelo marido, a buscar um tipo de atividade mais flexível, que lhe permitisse ficar mais tempo em casa. Influenciada por familiares, decidiu deixar seu emprego e, a contragosto, tornar-se empreendedora. Outro caso advém do empreendedor 5. Aposentado e com os filhos já formados e criados, pretendia, naquele momento, simplesmente, aproveitar a vida. Nunca havia pensado em se tornar empresário. Isso até o dia em que um antigo companheiro de trabalho, que pretendia criar uma empresa, vem convidá-lo para sócio. Finalmente, outro exemplo vem com o empreendedor 6, que havia construído longa carreira em uma empresa de grande porte, onde detinha posição gerencial. Quando surgiu um programa de demissão incentivado, ele decidiu deixar seu emprego, pensado em abrir uma empresa, que atendesse seu antigo empregador.

A Tabela 2, a seguir, apresenta os resultados obtidos com a análise fatorial. Observa-se que a amostra apresenta agrupamentos que, quanto à classificação, representam motivos que podem estar associados tanto à oportunidade quanto à necessidade, ou, então, desvinculados de ambos. 
Tabela 2

Matriz de Componentes Rotacionada

\begin{tabular}{|c|c|c|c|c|c|c|}
\hline \multirow{2}{*}{ Questões/ Motivos } & \multicolumn{6}{|c|}{ Componentes } \\
\hline & 1 & 2 & 3 & 4 & 5 & 6 \\
\hline $\begin{array}{l}\text { Dar continuidade ou ampliar os negócios } \\
\text { da família }\end{array}$ & .775 & .114 & -.176 & .005 & -.154 & .124 \\
\hline $\begin{array}{l}\text { Dar ocupação para outros membros de sua } \\
\text { família }\end{array}$ & .672 & .063 & .127 & .104 & .286 & -.201 \\
\hline $\begin{array}{l}\text { Possibilitar o uso de experiência/ } \\
\text { influência familiar. }\end{array}$ & .661 & .166 & -.157 & .343 & -.222 & -.033 \\
\hline $\begin{array}{l}\text { Facilitar ou possibilitar o uso de } \\
\text { conhecimentos/ relacionamentos na área. }\end{array}$ & .026 & .709 & -.195 & .085 & -.206 & -.131 \\
\hline $\begin{array}{l}\text { Desejar ter o próprio negócio/ tornar-se } \\
\text { independente }\end{array}$ & -.025 & .688 & -.057 & -.133 & .471 & .003 \\
\hline Ter tempo disponível & .379 & .567 & .333 & -.010 & -.087 & -.023 \\
\hline Necessitar aumentar a renda & .284 & .539 & .270 & -.016 & .341 & .086 \\
\hline Acessar a recursos do FGTS & .028 & -.017 & .740 & .046 & .153 & -.086 \\
\hline Estar desempregado & -.213 & .058 & .738 & .099 & -.136 & .013 \\
\hline Ter capital disponível & .417 & -.112 & .442 & .119 & .073 & .398 \\
\hline $\begin{array}{l}\text { Ser convidado para participar como sócio } \\
\text { da empresa }\end{array}$ & .087 & -.005 & -.014 & .791 & .114 & .132 \\
\hline $\begin{array}{l}\text { Sofrer pressão/ influência de outras } \\
\text { pessoas }\end{array}$ & .160 & -.047 & .185 & .731 & -.068 & -.071 \\
\hline Estar insatisfeito com o emprego & -.078 & .009 & .016 & .059 & .842 & -.083 \\
\hline Identificar uma oportunidade de negócio & -.091 & .133 & .045 & .411 & -.062 & .742 \\
\hline $\begin{array}{l}\text { Inserir-se em programas de demissão } \\
\text { voluntária }\end{array}$ & -.013 & .251 & .154 & .335 & .083 & -.628 \\
\hline
\end{tabular}

Os resultados da análise fatorial indicam que existe uma adequação para aplicação da análise fatorial, Kaiser-Meyer-Olkin Measure of Sampling Adequacy $=0,629$. O teste Bartlett's Test of Sphericity apresenta um qui quadrado $=379,078$ com sig. 0,000, indicando a existência de relações entre indicadores para aplicação da (AF). A análise da matriz anti- imagem apresenta, em sua diagonal, correlações acima de 0,50 , o que nos proporciona indícios da existência de representação das variáveis pelos fatores. Para identificar o número de fatores, utilizou-se o critério do autovalor (Critério de Kaiser) acima de 1 . O autovalor indica o quanto o fator consegue explicar da variância total.

As comunalidades, que representam a proporção da variância para cada variável que é explicada pelos componentes extraídos, apresentaram-se superiores a 0,5. Destaca-se que alcançaram, na variável identificação de uma oportunidade, o valor mais alto $(0,752)$. A Tabela 3 , a seguir, apresenta a variância total explicada pelos fatores, indicando que esta atinge um percentual acumulado de $63,528 \%$, considerado satisfatório. 
Tabela 3

Total da Variância Explicada

\begin{tabular}{|c|c|c|c|c|c|c|c|c|c|}
\hline \multirow{2}{*}{ Componentes } & \multicolumn{3}{|c|}{ Autovalores iniciais } & \multicolumn{3}{|c|}{$\begin{array}{c}\text { Soma dos quadrados das } \\
\text { cargas }\end{array}$} & \multicolumn{3}{|c|}{$\begin{array}{l}\text { Soma dos quadrados das } \\
\text { cargas - Rotacionada }\end{array}$} \\
\hline & Total & $\begin{array}{c}\text { \% da } \\
\text { variância }\end{array}$ & $\begin{array}{c}\% \\
\text { acumulado }\end{array}$ & Total & $\begin{array}{c}\text { \% da } \\
\text { variância }\end{array}$ & $\begin{array}{c}\% \\
\text { acumulado }\end{array}$ & Total & $\begin{array}{c}\text { \% da } \\
\text { variância }\end{array}$ & $\begin{array}{c}\% \\
\text { acumulado }\end{array}$ \\
\hline 1 & 2.697 & 17.977 & 17.977 & 2.697 & 17.977 & 17.977 & 1.981 & 13.210 & 13.210 \\
\hline 2 & 1.820 & 12.133 & 30.111 & 1.820 & 12.133 & 30.111 & 1.730 & 11.536 & 24.746 \\
\hline 3 & 1.734 & 11.561 & 41.672 & 1.734 & 11.561 & 41.672 & 1.644 & 10.963 & 35.709 \\
\hline 4 & 1.146 & 7.640 & 49.312 & 1.146 & 7.640 & 49.312 & 1.624 & 10.828 & 46.537 \\
\hline 5 & 1.089 & 7.258 & 56.570 & 1.089 & 7.258 & 56.570 & 1.326 & 8.842 & 55.379 \\
\hline 6 & 1.044 & 6.958 & 63.528 & 1.044 & 6.958 & 63.528 & 1.222 & 8.149 & 63.528 \\
\hline 7 & .858 & 5.723 & 69.251 & & & & & & \\
\hline 8 & .825 & 5.498 & 74.749 & & & & & & \\
\hline 9 & .733 & 4.889 & 79.638 & & & & & & \\
\hline 10 & .630 & 4.198 & 83.836 & & & & & & \\
\hline 11 & .589 & 3.928 & 87.765 & & & & & & \\
\hline 12 & .559 & 3.728 & 91.492 & & & & & & \\
\hline 13 & .503 & 3.352 & 94.845 & & & & & & \\
\hline 14 & .456 & 3.038 & 97.882 & & & & & & \\
\hline 15 & .318 & 2.118 & 100.000 & & & & & & \\
\hline
\end{tabular}

Nota. Método de extração: análise de componentes principais.

Os quinze motivos puderam ser agrupadas em seis conjuntos de componentes. São eles: $\mathbf{1}^{\mathbf{0}}$ componente: dar continuidade ou ampliar os negócios da família; dar ocupação a familiares; possibilidade de usar experiência/influência familiar; $\mathbf{2}^{\mathbf{0}}$ componente: facilidade ou possibilidade de usar relacionamentos na área; desejo de ter seu próprio negócio/tornar-se independente; presença de tempo disponível; necessidade/vontade de aumentar renda; $3^{\circ}$ componente: demissão com FGTS; desemprego; presença de algum capital disponível; $\mathbf{4}^{\mathbf{0}}$ componente: convite para participar como sócio da empresa; influência/pressão de outras pessoas; $5^{\circ}$ componente: insatisfação com emprego; $\mathbf{6}^{\mathbf{0}}$ componente: identificação de uma oportunidade de negócio; usufruto de programa de demissão voluntária.

Observa-se que a hipótese de que as variáveis se agrupassem em componentes que representassem, inclusive, os construtos oportunidade e necessidade como motivos alternativos para a criação de um empreendimento, não foi confirmada. Aliás, ocorreu dispersão entre os motivos. Os resultados mostram não apenas que as variáveis pesquisadas não se agrupam segundo uma lógica binária, como, também, que interagem no contexto de uma lógica diferente, baseada em seis componentes ou fatores.

Analisando-se o conteúdo de cada um desses componentes, observa-se que os mesmos são dotados de relativa consistência ou coerência interna. Isso permite classificá-los ou designá-los segundo suas respectivas naturezas, ficando: (a) influência familiar (motivos: dar continuidade ou ampliar os negócios da família; dar ocupação a familiares; possibilidade de usar experiência/influência familiar); (b) atributos/expectativas pessoais (motivos: facilidade ou possibilidade de usar relacionamentos na área; desejo de ter seu próprio negócio/tornar-se independente; disponibilidade de tempo; aumentar 
renda); (c) ambiente externo/mercado de trabalho (motivos: demissão com FGTS; desemprego; capital disponível para aplicação); (d) influência externa/de terceiros (motivos: convite para participar como sócio da empresa; influência/pressão de outras pessoas); (e) insatisfação com emprego (motivo: insatisfação com emprego); (f) oportunidade (motivos: identificação de uma oportunidade de negócio; usufruto de programa de demissão voluntária).

\section{Considerações Finais}

Os resultados, embora limitados a dado universo de interesse, permitem algumas reflexões. Observa-se, antes de mais nada, que se rejeita, aqui, a hipótese $\mathrm{H}_{0}$, de que oportunidade e necessidade abarcam o conjunto de motivações para a abertura de uma empresa e aceita-se a $\mathrm{H}_{1}$ : oportunidade e necessidade não abarcam o conjunto de motivação para a criação de uma empresa. A análise fatorial sugere que as motivações extrapolam a lógica binária oportunidade/necessidade, e agrupam-se em seis componentes: identificação de oportunidade; atributos/expectativas pessoais; ambiente externo - em particular associado ao mercado de trabalho; influência de terceiros, insatisfação com emprego; influência familiar.

Esses resultados associam-se a premissas diferentes de algumas adotadas pelo GEM (Antunes et al., 2012; Duarte et al., 2011). Primeiramente, os motivos oportunidade necessidade não se mostraram capazes de explicar todo o processo, o que sugere a presença de motivações múltiplas (Sebrae, 2007a, 2007b; Sivapalan \& Balasundaram, 2012; Storey, 2006; Ummah \& Gunapalan, 2012; Vale et al., 1998; Woods, 2006). Em segundo lugar, os motivos oportunidade e necessidade não parecem ser, necessariamente, excludentes. Um indivíduo que se sente compelido a abrir um empreendimento por falta de alternativa ou por necessidade de sobrevivência pode, eventualmente, ficar mais atento a oportunidades, procurando, antes, identificar um espaço adequado para investir e criar o seu empreendimento (ver, por exemplo, caso mencionado do empreendedor 1. Os dados são coerentes com proposições de autores como Smallbone e Welter (2001), Williams (2008) e Williams e Round (2009) sobre a possibilidade de convergência entre os motivos oportunidade e necessidade.

Salienta-se que o fator influência familiar, no formato aqui identificado, não havia sido registrado em literatura prévia. Mesmo quando Ummah and Gunapalan (2012) introduzem o elemento família, eles consideram, especificamente, o background familiar. Já Pozin (2013) menciona, exclusivamente, a escolha do empreendedorismo motivada pelo fato de permitir maior flexibilidade e tempo para afazeres domésticos. Nenhum deles aborda o tema família, como aqui tratado. Isso é importante, sobretudo considerando-se a criação de uma empresa movida pelo desejo de dar ocupação a membros da família em dificuldades, citado por parcela não desprezível da amostra (15\%). Tal fenômeno pode ser caracterizado como um tipo de redistribuição (de pai para filho, por exemplo), recorrendo-se a uma terminologia utilizada por Barber (1995).

A partir dos resultados obtidos, novas indagações podem ser aventadas, capazes de serem exploradas em futuras pesquisas. Uma delas diz respeito a possíveis vinculações entre as motivações e os perfis ou o desempenho de empreendedores. Duas grandes questões aí se colocam. Em primeiro lugar, se as diferenciações de perfil de empreendedores - em termos, por exemplo, de gênero, idade, inserção em certos tipos de redes, escolaridade, etc. - poderiam, eventualmente, influenciar as motivações. Em segundo lugar, se a natureza das motivações - a exemplo da criação de empresas baseada na crença da identificação de uma oportunidade de negócio ou, então, por pressão do desemprego e falta de alternativa ou, ainda, por influência familiar - poderia, eventualmente, afetar o desenvolvimento do empreendimento e do próprio empreendedor. São questões instigantes, que merecem ser exploradas em novas pesquisas.

Os resultados também geram alguns elementos de reflexão para entidades que atuam na área do empreendedorismo. Em primeiro lugar, programas de estímulo ao empreendedorismo poderiam ser concebidos, levando-se em consideração diferenças de motivações entre indivíduos. Diferentes 
indivíduos podem ser movidos por diferentes motivações. Conhecê-las permite melhor formatar tais programas. Se, de fato, os empreendedores movidos por oportunidade apresentam um perfil mais competitivo - hipótese a ser comprovada em novas pesquisas - então, deve-se dar maior atenção a empreendedores movidos, por exemplo, pela pressão do desemprego. Sugere-se, nesse caso, priorizar e direcionar programas especializados de treinamento e apoio para indivíduos provenientes de atividades produtivas e setores econômicos em fase de reestruturação ou conversão produtiva e, como tal, mais afetados pelo desemprego. Um operário altamente especializado, porventura demitido de uma grande aciaria em processo de reestruturação, difere bastante, em temos de habilidades e necessidades, de um proveniente no setor automotivo ou, então, de um empregado remanescente do sistema financeiro. Diferenças no perfil ocupacional são fundamentais e devem ser consideradas em programas de capacitação, ainda que indivíduos tenham, eventualmente, sido movidos ao empreendedorismo por um mesmo motivo (no caso, o desemprego).

Em segundo lugar, parece ilusório pretender que, entre as motivações para empreender, insira-se aproveitar incentivo governamental. Tal motivação, embora introduzida pelo Sebrae em pesquisas prévias (2007a, 2007b), não vem sendo objeto de nenhuma citação. Isso não quer dizer que políticas governamentais não sejam importantes. Pelo contrário. No entanto, fatores ambientais que poderiam influenciar o empreendedorismo parecem estar mais associados ao dia a dia do indivíduo e à sua sobrevivência. Certamente, determinados tipos de políticas públicas, mais ou menos expansionistas ou, então, contracionistas, e, como tal, capazes de afetar índices de emprego/desemprego, podem, eventualmente, afetar o empreendedorismo. Novos estudos poderiam enfocar, em particular, tais temas.

À luz dos resultados, seria possível tecer alguns comentários sobre escopo e metodologias, visando novas investigações. Embora pesquisas de natureza quantitativa sejam de fundamental importância - inclusive por permitirem medidas e comparações objetivas entre diferentes realidades - a exemplo da pesquisa do GEM - a complementação de pesquisas quantitativas com investigações de natureza qualitativa apresenta muitas vantagens, como permitir melhor identificar e contextualizar os motivos e mapear as nuances presentes nas motivações que levam ao empreendedorismo. Nesse contexto, futuras pesquisas, envolvendo diferentes regiões e setores produtivos seriam muito apropriadas.

\section{Referências}

Aldrich, H. E., \& Cliff, J. E. (2003). The pervasive effects of family on entrepreneurship: toward a family embeddedness perspective. Journal of Business Venturing, 18(5), 573-596. doi: 10.1016/S0883-9026(03)00011-9

Antunes, A. L., Pereira, F. F., Sarfati, G., Righi, G. B., Felix, J. C., Pansarella, L., Aidar, M., Salusse, M., Macedo, M. M. de., Neto, M. T., Guimarães, M. L., Fernandes, R. J. R., Greco, S. M. S. de., Andreassi, T., \& Nassif, V. (2012). GEM Global Entrepreneurship Monitor: empreendedorismo no Brasil (Relatório de Pesquisa/2012). Curitiba, IBQP. Recuperado de http://www.ibqp.org.br/upload/tiny_mce/Download/Empreendedorismo\%20no\%20Brasil\%202 012.pdf

Aranson, R. (1991). Self-employment: a labor market perspective. New York: ILR Press.

Barber, B. (1995). All economies are embedded: the career of a concept and beyond. Social research, 62(2), 387-413.

Bardin, L. (2004). Análise de conteúdo. Lisboa: Edições 70.

Baum, J. R., Frese, M., Baron, R. B., \& Katz, J. A. (2007). Entrepreneurship as an area of psychology study: an introduction. In J. R. Baum, M. Frese, \& R. B. Baron (Eds.), The psychology of Entrepreneurship (pp. 1-18). New Jersey: Lawrence Erlbaum Associates Inc. Publishers. 
Block, J. H., \& Sandner, P. (2009). Necessity and opportunity entrepreneurs and their duration in selfemployment: evidence from German micro data. Journal of Industry Competition and Trade, 9(2), 117-137. doi: 10.1007/s10842-007-0029-3

Block, J. H., \& Wagner, M. (2010). Necessity and opportunity entrepreneurs in Germany: characteristics and earnings differentials. Schmalenbach Business Review, 62(2), 154-174.

Corrar, L. J., Paulo, E., \& Dias, J. M., Filho. (2007). Análise multivariada para os cursos de Administração, ciências contáveis e economia. São Paulo: Atlas.

Damásio, B. F. (2012). Uso da análise fatorial exploratória em psicologia. Revista Avaliação Psicológica, 11(2), 213-228.

Duarte, E. C. V. G. de, Sarfati, G., Machado, J. P., Felix, J. C., Pansarella, L., Aidar, M., Neto, M. T., Salusse, M., Fernandes, R. R., Ozon, R. H., Friedlaender, R. H. Jr., Greco, S. M. S. S. de, Andreassi, T., Moroz, V., \& Nassif, V. (2011). GEM Global Entrepreneurship Monitor: empreendedorismo no Brasil (Relatório de Pesquisa/2011). Curitiba: IBQP. Recuperado de http://www.ibqp.org.br/upload/tiny_mce/Empreendedorismo\%20no\%20Brasil\%202011.pdf

Festinger, L. (1957). A theory of cognitive dissonance. Evanston: Peterson

Friedman, R. E. (1986). Entrepreneurial renewal in the industrial city. Annals of the American Academic Political Science, 488(1), 35-46. doi: 10.1177/0002716286488001003

Gartner, W. B. (1989). Who is the entrepreneur? Is the wrong question. Entrepreneurship Theory and Practice, $\quad 47-68 . \quad$ Recuperado de http://business2.fiu.edu/1660397/www/definitions\%20of\%20entrepreneurship/gartner_1989.pdf

Global Entrepreneurship Monitor. (n.d.). What is GEM?. Recuperado de www.gemconsortium.org/What-is-GEM

Global Entrepreneurship Monitor. (2011). Empreendedorismo no Brasil. Recuperado de http://gestaoportal.sebrae.com.br/customizado/estudos-e-pesquisas/temasestrategicos/empreendedorismo/Livro\%20GEM\%20Brasil\%202011.pdf

Hair, J. F. (2005). Análise multivariada de dados. Porto Alegre: Bookman

Kautonen, T., \& Palmroos, J. (2010). The impact of a necessity-based start-up on subsequent entrepreneurial satisfaction. International Entrepreneurship and Management Journal, 6(3), 285-300. doi: 10.1007/s11365-008-0104-1

Kirzner, I. M. (1979). Perception, opportunity, and profit: studies in the theory of entrepreneurship. Chicago: University of Chicago Press.

Kon, A. (2001). Perfil dos trabalhadores por conta própria no Brasil (Relatório de Pesquisa $\mathrm{n}^{\circ}$ 31/2001).

Recuperado

de http://bibliotecadigital.fgv.br/dspace/bitstream/handle/10438/3122/Rel\%20312001.pdf?sequence $=1$

Llisterri, J. J., Kantis, H., Angelelli, P., \& Tejerina, L. (2006). Is youth entrepreneurship a necessity or an opportunity? A first exploration of household and new enterprise surveys in Latin America. (Relatório de Pesquisa/2006). Recuperado de http://idbdocs.iadb.org/wsdocs/getdocument.aspx?docnum=1448848

Lohrke, F., \& Landström, H. (2010). History matters in entrepreneurship research. In H. Landström \& F. Lohrke (Eds.), Historical foundations of entrepreneurship research (pp. 1-14). Massachusetts: Edward Elgar Publishing. 
McClelland, D. C. (1972). A sociedade competitiva. Rio de Janeiro: Expressão e Cultura.

Nuttin, J., Lorion, R. P., \& Dumas, J. E. (1984). Motivation, planning, and action: a relational theory of behavior dynamics. Leuven: Leuven University Press.

Plehn-Dujowich, J. M. (n.d.). The dynamic relationship between entrepreneurship, unemployment, and growth: evidence from U.S. industries. Recuperado de http://www.sba.gov/sites/default/files/rs394tot.pdf

Pozin, I. (2013, February 19). 10 best reasons to be an entrepreneur. Recuperado de http://www.inc.com/ilya-pozin/10-best-reasons-to-be-entrepreneur.html

Reynolds, P. D., Bygrave, W. D., \& Autio, E. (2002). GEM Global Entrepreneurship Monitor: relatório de pesquisa Global Entrepreneurship Monitor (Relatório de Pesquisa/2002). Recuperado de http://www.ibqp.org.br/upload/tiny_mce/Empreendedorismo\%20no\%20Brasil\%202002\%20$\% 20$ Relat\%C3\%B3rio.pdf

Schatz, S. P. (1971). On achievement and economic growth: a critical appraisal. In P. Kilby (Ed.), Entrepreneurship and economic development (pp. 183-190). New York: The free Press.

Secretaria de Assuntos Estratégicos. (2013). Vozes da nova classe média (Caderno 3). Recuperado de http://www.sae.gov.br/site/wp-content/uploads/3\%C2\%BA-Caderno-VCM-Vers\%C3\%A3oFinal-20130506.pdf

Serviço Brasileiro de Apoio às Micro e Pequenas Empresas. (2013). Os donos de negócios no Brasil, por regiões e por unidades da federação. (Série Estudos e Pesquisas). Brasília: Sebrae.

Serviço Brasileiro de Apoio às Micro e Pequenas Empresas. (2007a). Fatores condicionantes e taxa de mortalidade de MPE (unidades de federação: São Paulo). Brasília: Autor.

Serviço Brasileiro de Apoio às Micro e Pequenas Empresas. (2007b). Fatores condicionantes e taxa de mortalidade de MPE (unidades de federação: Minas Gerais). Brasília: Autor.

Sivapalan, A., \& Balasundaram, N. (2012). Level of entrepreneurial intention of the management undergraduates in the University of Jaffna, Sri Lanka: scholars and undergraduates perspective. South Asian Academic Research Journals, 2(10), 24-42.

Smallbone, D., \& Welter, F. (2001). Entrepreneurship in transition economies: necessity or opportunity driven? Small Business Economic, 16(4), 249-262.

Stevenson, W. J. (2001). Estatística aplicada à administração. São Paulo: Harper.

Storey, D. (2006). Book review: the economics of self-employment and entrepreneurship. International Small Business Journal, 24(1), 101-103. doi: 10.1177/0266242606061106

Townsend, D. M., Busenitz, L. W., \& Arthurs, J. D. (2010). To start or not to start: outcome and ability expectations in the decision to start a new venture. Journal of Business Venturing, 25(2), $192-$ 202. doi: 10.1016/j.jbusvent.2008.05.003

Ummah, S. (2009). Entrepreneurial motivation and self-employment intention: an empirical study on management undergraduates in Sri Lanka. Journal of Management, 5(1), 87-96.

Ummah, S., \& Gunapalan, S. (2012). Factors influencing on entrepreneurial success: an empirical study on women headed families in Ampara and Batticaloa districts in Sri Lanka. International Journal of Business, Economics and Law, 1(1), 141-148. Recuperado de http://klibel.com/wpcontent/uploads/2012/12/FACTORS-INFLUENCING-ON-ENTREPRENEURIAL-SUCCESSAN-EMPIRICAL-STUDY-ON-WOMEN-HEADED-FAMILIES-AMPARA-ANDBATTICALOA-DISTRICTS-IN-SRI-LANKA.pdf 
Valarelli, M. M., \& Vale, G. M. V. (1997). Informalidade e cidadania: empreendimento informais no Rio de Janeiro. Rio de Janeiro: IBASE.

Vale, G. M. V., Aguiar, M. A. S., \& Andrade, N. A. (1998). Fatores condicionantes da mortalidade de empresas. Brasília: Edições Sebrae.

Williams, C. C. (2008). The motives of off-the-books entrepreneurs: necessity-or opportunity-driven? Springer Science, 5(2), 203-217. doi: 10.1007/s11365-008-0098-8

Williams, C. C., \& Round, J. (2009). Evaluating informal entrepreneurs' motives: evidence from Moscow. International Journal of Entrepreneurial Behavior \& Research, 15(1), 94-107. doi: $10.1108 / 13552550910934477$

Williams, C. C., Round, J., \& Rodgers, P. (2009). Evaluating the motives of informal entrepreneurs: some lessons from Ukraine. Journal of Developmental Entrepreneurship, 14(1), 59-71. doi: $10.1142 / \mathrm{S} 1084946709001144$

Woods, C. R. (2006). Asking the entrepreneur: an enquiry into entrepreneurial behavior. Personal Construct Theory \& Practice, 3(1), 1-12. Reciperado de http://www.pcpnet.org/journal/pctp06/woods06.pdf

Zalio, P. P. (2011). Sociologie économique des entrepreneurs. In P. Steiner, \& F. Vatin (Eds.), Traité de sociologie économique (pp. 573-607). Paris: Puf. 